\title{
Ultrastructure of the Envelope during Glucosamine Starvation and Penicillin Treatment of a Mutant of Escherichia coli
}

\author{
By K. LOUNATMAA, M. SARVAS AND J. WARTIOVAARA \\ Central Public Health Laboratory (State Serum Institute) SF-00280 Helsinki 28, \\ and the Electron Microscope Laboratory, University of Helsinki, Finland
}

(Received 8 March 1974)

INTRODUCTION

Lipopolysaccharide (LPS) is a major and characteristic constituent of the outer membrane of the envelope of enteric bacteria (Freer \& Salton, I97I). The proximal end of the LPS molecule - mainly composed of nonpolar lipid A - is an integral and indispensable component of the outer membrane (Osborn, 1973). The basic structure of lipid A is a glucosamine disaccharide substituted with fatty acids (Rietschel, Gottert, Luideritz \& Westphal, 1972). Synthesis of lipid A is thus expected to be completely blocked in a $g / m$ mutant of Escherichia coli $\mathrm{K} 12$ defective in glucosamine synthetase if no exogenous glucosamine is available (Sarvas, 1971; Wu \& Wu, 1971).

We have studied the effect of glucosamine starvation on the ultrastructure of the outer membrane and the cell envelope of a $\mathrm{glm}$ mutant. Glucosamine starvation would also be expected to affect the cell envelope by blocking the synthesis of peptidoglycan. The mutant lyses, or if grown in a medium of proper osmolality it becomes a spheroplast-like structure (Sarvas, 1971; Wu \& Wu, 1971). In order to investigate possible specific effects of the block of lipid A synthesis, we have compared the ultrastructure of the envelope during glucosamine starvation with the alterations caused by penicillin, which inhibits the synthesis of peptidoglycan only (Strominger, 1968).

\section{METHODS}

Bacteria and cultivation. The bacterial strains used were derivatives of Escherichia coli K12. Strain JC5O29 comes from the collection of A. J. Clark, Department of Bacteriology and Immunology, University of California, Berkeley, California, U.S.A. The strain was $\mathrm{Hfr}$ with the following genetic markers: $s p c, t h r, i l v$ and thi (genetic symbols according to Taylor, 1970). Strain EH3247 was a glm mutant of JC5029 defective in L-glutamine: D-fructose-6-phosphate aminotransferase (glucosamine synthetase) (Sarvas, 1971).

Bacteria were culivated at $37^{\circ} \mathrm{C}$ in an orbital incubator in yeast extract (YE) medium (composed of $1 \%$ of yeast extract, Difco) or L-broth ( $\%$ Bacto Tryptone, $0.5 \%$ yeast extract, $1 \% \mathrm{NaCl}$ and $0.025 \% \mathrm{CaCl}_{2}$ ), both supplemented with $200 \mu \mathrm{g}$ of $\mathrm{N}$-acetyl-D-glucosamine (GlcNAc) $\mathrm{ml}$ as indicated.

Spheroplast formation. An overnight culture was diluted 25 -fold into fresh YE medium or L-broth (supplemented with GlcNAc in the case of EH3247) and incubated to reach early exponential phase. The bacteria were centrifuged and resuspended in the same volume of fresh YE medium supplemented with sucrose $(15 \%, \mathrm{w} / \mathrm{v})$ but without GIcNAc (glucosamine spheroplast, $\left.\mathrm{EH}_{3247}\right)$ or with sucrose $(20 \% \mathrm{w} / \mathrm{v})$ and penicillin $\mathrm{G}(600$ or $200 \mu \mathrm{g} / \mathrm{ml}$ ) (penicillin spheroplast, JC5029). 
Electron microscopy. Two procedures were used for fixation. (i) Samples $(35 \mathrm{ml})$ of the bacterial culture were centrifuged at about $2000 \mathrm{~g}$ at $4{ }^{\circ} \mathrm{C}$ for $15 \mathrm{~min}$. The pellets were fixed with $2 \%$ glutaraldehyde and $\mathrm{I} \%$ osmium tetroxide in Ringer solution $(9 \cdot 0 \mathrm{~g} \mathrm{NaCl}, 0.42 \mathrm{~g}$ $\mathrm{KCl}, 0.25 \mathrm{~g} \mathrm{CaCl}_{2}$ in $\mathrm{I}$ l) containing $15 \%\left(\mathrm{w} / \mathrm{v}\right.$ ) sucrose and $0.02 \mathrm{M}^{-\mathrm{MgCl}_{2}}$ (in order to minimize the breakage of spheroplasts). (ii) The cells were prefixed before harvesting by adding $35 \mathrm{ml}$ of the bacterial culture to $10 \mathrm{ml}$ of the following solution: $1.5 \%$ glutaralde-

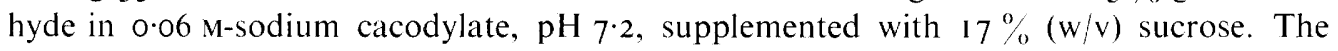
mixture was kept at $4{ }^{\circ} \mathrm{C}$ for $2 \mathrm{~h}$, after which it was centrifuged at about $2000 \mathrm{~g}$ at $4{ }^{\circ} \mathrm{C}$ for $15 \mathrm{~min}$. The pellet was washed twice with $0.2 \mathrm{M}-(7 \%, \mathrm{w} / \mathrm{v})$ sucrose in $0.1 \mathrm{M}$-sodium phosphate buffer. The pellets were then refixed at $4{ }^{\circ} \mathrm{C}$ with $1.25 \%$ glutaraldehyde in $0.1 \mathrm{M}-$ sodium cacodylate with $2 \mathrm{~mm}-\mathrm{MgCl}_{2}$ for $30 \mathrm{~min}$. The pellets were postfixed with $\mathrm{I} \%$ osmium tetroxide. Both methods (i) and (ii) yielded similar results.

The sections were obtained from Epon 8 I 2 -embedded samples and stained with uranyl acetate and lead citrate. Electron micrographs were taken with a Philips 300 electron microscope operating at $80 \mathrm{kV}$.

\section{RESULTS}

Glucosamine starvation in a medium with $15 \%$ sucrose affects the cellular morphology of the $g / m$ mutant in a way which resembles the formation of spheroplasts caused by penicillin treatment (Sarvas, I97 I Wu \& Wu, 197I). We have now found that the formation of these glucosamine spheroplasts (strain EH3247) depends on the conditions of cultivation. Without good aeration very few spheroplasts were found. Maximal and most rapid spheroplasting took place when organisms were first grown in L-broth supplemented with glucosamine and then shifted to YE medium containing $15 \%$ sucrose but no glucosamine. If the pregrowth also took place in YE medium the process was slower and the morphology of the spheroplasts was different.

Phase contrast microscopy did not reveal any differences between the effects of glucosamine starvation and penicillin in medium supplemented with sucrose. Both the morphology and the time course of the alterations were very similar, if $200 \mu \mathrm{g}$ penicillin $\mathrm{G} / \mathrm{ml}$ were used (strain EH3247 and JC5029). When bacteria were pregrown in L-broth, the first morphological changes were large protrusions of the envelope, usually in the middle of the rod about $30 \mathrm{~min}$ after the shift of medium. The protrusions enlarged in a few minutes to include the whole organism. Large crescent-shaped vacuoles were regularly seen in fully developed spheroplasts. No breakage of cells was visible; the extinction of the culture increased slightly. However, the extinction of a culture in the same medium but without sucrose began to drop when the protrusions appeared, indicating increased osmotic fragility of the bacteria. These findings agree well with earlier reports of the effects of penicillin on Escherichia coli (Lederberg \& St'Clair, 1958; Murray, Steed \& Elson, 1965).

For electron microscopic studies of the envelope, samples were taken at characteristic phases of spheroplast formation as determined by phase contrast microscopy and the extinction of the cultures. The effects of glucosamine starvation and penicillin were studied with the $g / m$ mutant EH3247 and its parent strain, JC5029, respectively.

Observations at low magnification confirmed the overall morphological changes seen with phase contrast microscopy. About 50 min after glucosamine deprivation or addition of penicillin some protrusions of the envelope were seen. Later the protrusions were enlarged at the expense of the rigid envelope and their number was increased. After about 90 min most of the bacteria had lost their regular morphology and had greatly increased in size. 

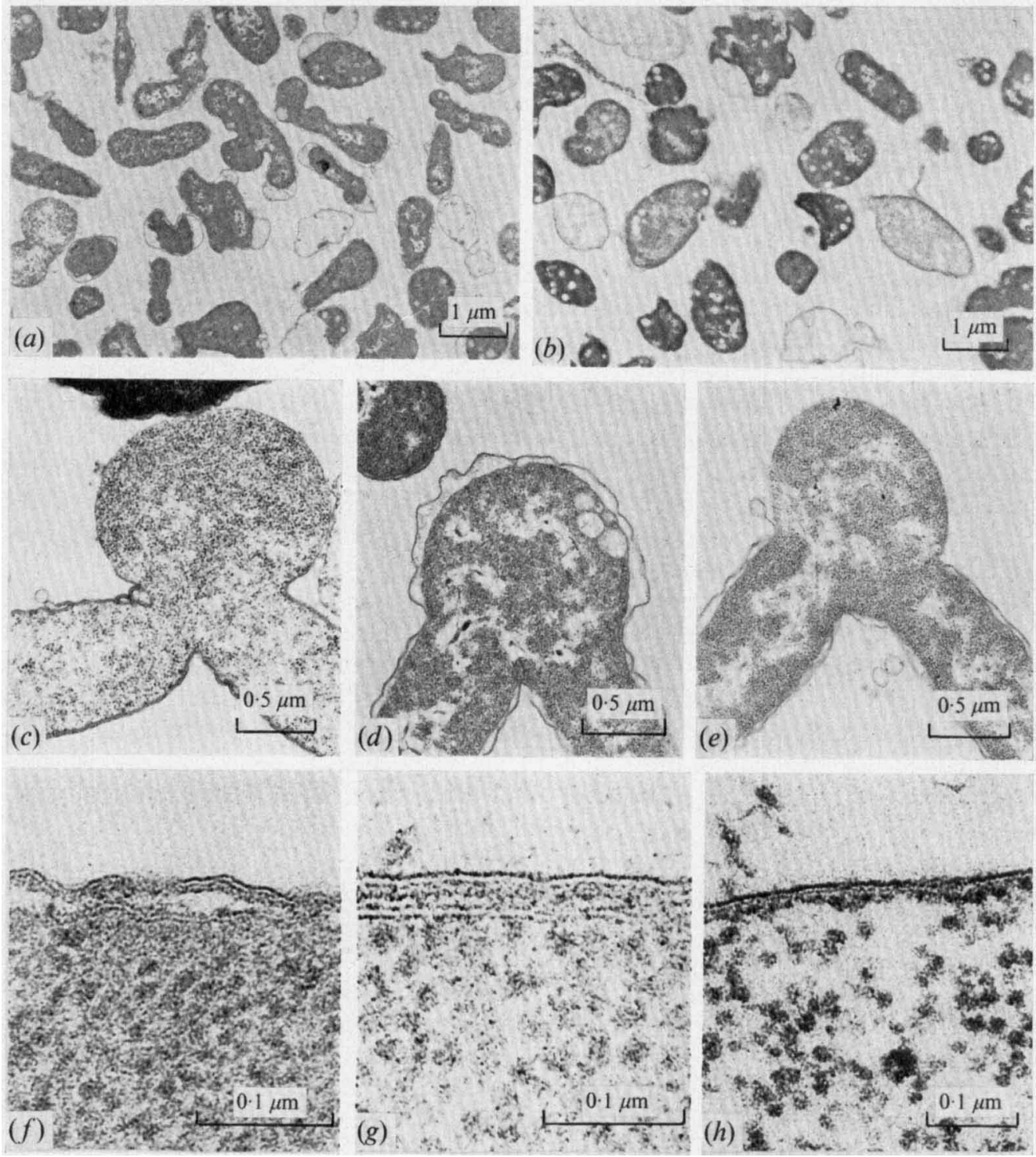

Fig. I. Effects of penicillin and glucosamine starvation on envelope of Escherichia coli JC5029 and its $\mathrm{g} / \mathrm{m}$ mutant EH3247. (a), (b) Extensive spheroplasting caused by penicillin treatment of $65 \mathrm{~min}(a)$ or glucosamine starvation of $75 \mathrm{~min}(b)$. Both cultures were pregrown in L-broth before the treatment. $(c),(d),(e)$ Protrusions caused on bacteria pregrown in YE medium. $(c)$ Effect of $80 \mathrm{~min}$ glucosamine starvation; the protrusion is covered by the cytoplasmic membrane only. (d) An early protrusion caused by penicillin and covered by both outer and cytoplasmic membranes. (e) A later protrusion with no outer membrane. $(f),(g),(h)$ The alterations of surface caused by glucosamine starvation. $(f)$ After Io min starvation, no changes are yet visible. $(g)$ An area of bulging of the envelope after $80 \mathrm{~min}$; outer membrane is flattened and the different layers of the membrane stand out more prominently. $(h)$ The wall of a protrusion covered by one unit membrane only, after 80 min starvation. Strain $\mathrm{SH} 3247$ was used for $(b),(c),(f),(g)$ and $(h)$, and strain JC5029 for $(a),(d)$ and $(e)$. 
Observations at higher magnification showed that the bulging of the envelope caused by penicillin was associated with separation of the cytoplasmic membrane from the outer membrane. This was seen in the very early protrusions; later, the detachment of the outer membrane was quite extensive (Fig. I $a$ ). There were very few cells with broken cytoplasmic or outer membranes. These findings are similar to earlier descriptions of penicillin spheroplasts of E. coli (Murray et al. 1965; Martin, 1963).

The ultrastructure of the protrusions and spheroplasts caused by glucosamine starvation were very similar to those caused by penicillin. However, the separation of cytoplasmic and outer membrane was not as extensive. No detachment of outer membrane was seen in early protrusions, and even at later stages of spheroplasting in most cases these membranes were separated only in conjunction with extensive breakage of the envelope (Fig. I $b$ ). The number of protrusions in all samples was much smaller than expected on the basis of phase contrast microscopy. The percentage of bacteria with protrusions seen by phase contrast microscopy increased by up to $50 \%$ during $65 \mathrm{~min}$ of glucosamine starvation. After electron microscopy no more than about $\mathrm{I} \%$ were found to carry protrusions in any of the samples studied. No such discrepancy was seen in the penicillin spheroplasts. This suggests that the preparation of spheroplasts for electron microscopy caused much more breakage of glucosamine spheroplasts than of penicillin spheroplasts.

The alterations of the envelope caused by glucosamine starvation or by penicillin changed in a characteristic way when the $g / m$ mutant or its parent strain were pregrown in low salt YE medium instead of L-broth. There was no difference in the generation time. In YE medium, however, the bacteria were considerably longer, although of regular and uniform length. In medium supplemented with sucrose, both glucosamine starvation and penicillin again caused the formation of protrusions of the envelope after about $50 \mathrm{~min}$. Phase contrast microscopy and electron microscopy at low magnifications showed that in both cases the protrusions were similar. They resembled small balloons attached with a very narrow stalk to the envelope. Later, the protrusions increased in size but the small area of the attachment to the wall did not enlarge. Again there was a discrepancy between the numbers of protrusions seen by phase contrast and electron microscopy even after a short time of glucosamine starvation, but not with penicillin. This seems to indicate that the protrusions caused by glucosamine starvation were more fragile than the protrusions caused by penicillin, in the sense that they ruptured easily during the preparation of the bacteria for electron microscopy.

Electron microscopy at high magnification showed that all well-defined protrusions caused by glucosamine starvation after growth in YE medium were devoid of outer membrane, and covered by the cytoplasmic membrane only (Fig. 1 c). The early protrusions caused by penicillin were usually covered by both membranes (Fig. I $d$ ), while the outer membrane of the later protrusions was again often peeled off (Fig. I $e$ ). The frequent breakage of the outer membrane may be due to the considerable amount of stretching to which the layers of the envelope were subjected; only a small area of the envelope seemed to be involved in the formation of the protrusions.

The structure of the boundaries of the protrusions are seen in more detail in Fig. I $(f)$ to $(h)$. The protrusions shown are those caused by glucosamine starvation after pregrowth in YE medium, when the stretching of envelope was maximal. However, the ultrastructure of the envelope of all protrusions was similar. The first changes were found in the areas of bulging of the wall (i.e. cross sections with large diameters). The characteristically undulating outer membrane (de Petris, 1967) was flattened (Fig. I $g$ ) and the different membrane layers stood out more prominently than in bacteria where no enlargement had taken place. 
The dark layer between the two membranes, corresponding to peptidoglycan (Murray et al. 1965; de Petris, 1967), was also clearly visible. The outer membrane of such bulging areas was occasionally broken and seemed to be peeling off. In later samples most of the unbroken organisms with clearly enlarged diameters were covered by one unit membrane only (Fig. 1 h).

The morphological changes of the envelope caused by glucosamine starvation and penicillin were very similar. This seems to indicate that the main effect of glucosamine starvation on the structure of the envelope is the disturbance of the synthesis of the peptidoglycan. If the lack of glucosamine also interfered with the synthesis of lipid A and the outer membrane, it was not reflected as morphological changes by electron microscopy.

We are grateful to Dr P. H. Mäkelä for constructive criticism and Mrs T. Koro and Miss E. Kujamäki for their technical help. Financial support has been provided by the Sigrid Jusélius Foundation (to M.S. and J.W.).

\section{REFERENCES}

Freer, J. H. \& Salton, M. R. J. (I97I). The anatomy and chemistry of Gram-negative cell envelope. In Microbial Toxins, vol. 4, pp. 67-126. Edited by G. Weinbaum, S. Kadis and S. J. Ajl. New York and London: Academic Press.

Lederberg, J. \& St`Clair, J. (1958). Protoplasts and L-type growth of Escherichia coli. Journal of Bacterio$\log y$ 75, I43-I 60.

Martin, H. H. (1963). Bacterial protoplasts - a review. Journal of Theoretical Biology 5, I-34.

Murray, R. G. E., Steed, P. \& Elson, H. E. (1965). The location of the mucopeptide in section of the cell wall of Escherichia coli and other Gram-negative bacteria. Camadian Journal of Microbiology Ir, $547-560$.

OSBORN, M. J. (1973). Mechanism of Assembly of the Outer Membrane of Salmonella. Oral communication, Ist International Congress for Bacteriology, Jerusalem.

DE PETRIS, S. (1967). Ultrastructure of the cell wall of Escherichia coli and chemical nature of its constituent layer. Journal of Ultrastructure Research $\mathbf{1 9}, 45-83$.

Rietschel, E. T., Gottert, H. Lüderitz, O. \& Westphal, O. (I972). Nature and linkages of the fatty acids present in the lipid-A component of Salmonella lipopolysaccharides. European Journal of Biochemistry 28, $166-173$.

Sarvas, M. (197I). Mutant of Escherichia coli K-I2 defective in D-glucosamine biosynthesis. Journal of Bacteriology I05, 467-471.

Strominger, J. L. (I968). Enzymatic reactions in bacterial cell wall synthesis sensitive to penicillins and other antibacterial substances. In Microbial Protoplasts, Spheroplasts and L-forms, pp. 55-61. Edited by L. B. Gruze. Baltimore: Williams and Wilkins.

TAyLOR, A. L. (1970). Current linkage map of Escherichia coli. Bacteriological Reviews 34, I55-175.

WU, H.C. \& WU, T.C. (1971). Isolation and characterization of a glucosamine-requiring mutant of Escherichia coli k-12 defective in glucosamine-6-phosphate synthetase. Journal of Bacteriology ro5. 455-466. 